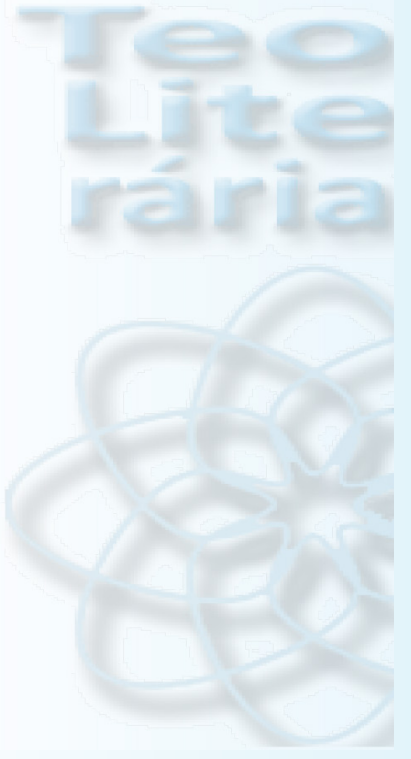

Arquivo enviado em

$30 / 06 / 2019$

e aprovado em

27/07/2019.

V. $9-$ N. $18-2019$

* Mestre em Ciências da Religião pela Universidade

PResbiteriana Mackenzie, e capelão militar do

Exército Brasileiro. Contato:

<christian@ipb.org.br>.

\section{A PESQUISA SOBRE RELIGIÃO E HISTÓRIAS EM QUADRINHOS NO BRASIL}

\author{
The research on religion \\ and comics in Brazil
}

\section{Christian David Soares Bitencourt}

\section{Resumo}

O presente artigo faz um mapeamento da pesquisa brasileira sobre histórias em quadrinhos (HQs) e religião. Trata-se de uma revisão de literatura cuja finalidade é averiguar o estado da arte desta pesquisa no Brasil. Para tanto, os artigos são reunidos em quatro categorias: teologia e HQs (investigando a abordagem teológica aos quadrinhos), quadrinhos e ciências da religião (analisando o fenômeno religioso nas $\mathrm{HQs}$ à luz da sociologia, história, estudos de gênero e representação racial, e etc.), $\mathrm{HQs}$ e ensino religioso (identificando os quadrinhos como recursos para a sala de aula), quadrinhos e divulgação religiosa (pesquisando como as HQs tornam-se mídia para a divulgação de ensinamentos religiosos), e quadrinhos como expressão espiritual ou arte visionária (tratando das HQs autorais que expressam a relação entre poesia e espiritualidade, e/ou são produzidas a partir de estados não-ordinários de consciência), com artigos que estão na zona limítrofe entre duas ou mais classificações.

Palavras-chave: Histórias em quadrinhos. Teologia do cotidiano. Teologia nerd. Religião e quadrinhos. 


\section{Abstract}

The present article maps Brazilian research on comics books (CB) and religion. This is a review of texts whose purpose is to check the state of the art of this research in Brazil. To do so, the articles are grouped into four categories: theology and CB (investigating the theological approach to comics), comics and religion sciences (analyzing the religious phenomenon in comics in the light of sociology, history, gender studies and racial representation, and etc.), CB and religious teaching (identifying comics as resources for the classroom), comics and religious diffusion (researching how comics become media for the dissemination of religious teachings), and comics as a spiritual expression or visionary art (dealing with authorial CB that express the relationship between poetry and spirituality, and / or are produced from non-ordinary states of consciousness), with articles that are in the borderline between two or more classifications.

Key words: Comics. Theology of everyday life. Nerd theology. Religion and comics.

\section{Introdução}

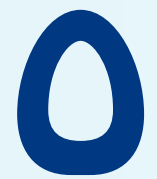

s estudos sobre Histórias em Quadrinhos (HQs) no Brasil têm crescido ano a ano. São abordagens a partir das mais variadas áreas, desde a história até a psicologia, passando por educação, sociologia e matemática, dentre muitas outras faces do conhecimento. A pesquisa que se debruça sobre os quadrinhos a partir dos estudos da religião, no entanto, ainda é incipiente.

Quando Cristina Xavier publica "Spawn, o soldado do inferno" em 2004, fruto de seu mestrado no ano anterior, dá-se início a uma leitura científica da relação entre religião e HQs. Ainda que o foco fosse uma abordagem junguiana dos mitos e arquétipos presentes na história do personagem, a busca pelo viés da religiosidade de alguma forma inaugura uma linha de pesquisa.

Desde então, o estudo da religião nas histórias em quadrinhos tem se desenvolvido progressivamente. Conquanto estejam em seus estágios iniciais, as pesquisas neste sentido já revelam uma 
grande diversidade: há trabalhos concentrados no mercado de quadrinhos norte-americano e outros no brasileiro (e alguns que se detêm no mangá e na bande dessinée), nas histórias comerciais e nas autorais, nas produções independentes e nas institucionais, na divulgação, na recepção e no processo criativo das histórias. Enfim, muitos são os vieses a partir dos quais a investigação se constrói.

O objetivo deste artigo é realizar um mapeamento da pesquisa brasileira sobre quadrinhos e religião. Trata-se de uma revisão de literatura cuja finalidade é averiguar o estado da arte desta pesquisa no Brasil. Ainda que a exploração não seja exaustiva, ela é abrangente ao ponto de servir como porta de entrada para os pesquisadores que almejam estudar este tema. Os textos são reunidos em quatro categorias: teologia e HQs, quadrinhos e ciências da religião, HQs e ensino religioso, quadrinhos e divulgação religiosa, e quadrinhos como expressão espiritual ou arte visionária, com artigos que estão na zona limítrofe entre duas ou mais classificações.

\section{Teologia e Histórias em Quadrinhos}

Grande parte dos textos sobre HQs e religião publicados no Brasil se refere ao diálogo entre os quadrinhos e a teologia. Fazendo uso de vários aportes teóricos distintos, os pesquisadores têm discutido os possíveis temas teológicos que surjam a partir da arte sequencial.

Dentre os autores que tratam desta relação, destaca-se o nome de luri Andréas Reblin, pelo pioneirismo e relevância de sua produção nesta área. Já em 2005, em "Para o alto e avante!", Reblin (2005) discute o papel da teologia com relação à cultura a 
partir das histórias de super-heróis. Para ele, enquanto produtos culturais, os personagens dos quadrinhos podem expressar o sagrado e a relação humana com o transcendente. Isto se dá porque a raiz do mundo mágico dos super-heróis e suas "histórias de encantamento" se encontra na imaginação e esta é responsável pelo universo simbólico, incluindo aí a experiência religiosa e sua expressão.

Em "O X da Questão", Reblin (2007a) extrai alguns temas teológicos e filosóficos com base na análise da adaptação cinematográfica do universo dos X-Men (grupo de super-heróis mutantes da Marvel). A partir de um diálogo com Kierkegaard, conclui-se que a força motriz do supergrupo mutante é amar o bem e que esta força se expressa na doação incondicional ao próximo, elemento que está presente na experiência de várias religiões.

Mas de que maneira é possível estabelecer esta interface entre teologia e HQs? Em "A teologia e a saga dos super-heróis”, Reblin (2010) faz uso da abordagem teológica à literatura para construir o diálogo com a narrativa dos quadrinhos. Parte-se do pressuposto que é possível encontrar o religioso ou o teológico numa narrativa a partir do "conjunto de elementos que constituem a experiência literária: o cenário, o enredo, os diálogos, as ações, os símbolos e os valores que se imiscuem nestes e a interatividade entre todos" (REBLIN, 2010, p. 14). No caso dos quadrinhos, e em especial do gênero da superaventura, esta experiência ganha sua força no conceito do herói como arquétipo presente no ser humano. Se o herói é aquele que, por suas ações, mantém acesa a chama da esperança de mudança numa determinada realidade, o super-herói é quem potencializa esta esperança em sua luta contínua contra o mal. Ao destrinchar este arquétipo heroico (ou super-heroico), é 
possível encontrar os temas teológicos e os símbolos religiosos que lá se manifestam.

Reblin ainda propõe, neste artigo, três vieses a partir dos quais pode-se perceber a presença da religião no gênero da superaventura. Primeiro, e por óbvio, há as narrativas de super-heróis que possuem elementos explicitamente religiosos, "quando os autores incluem intencionalmente elementos de tradições religiosas, citações de textos sagrados, etc. e a maneira como eles aparecem no texto, a forma como participam da trama central" (REBLIN, 2010, p. 19). Um segundo viés, segundo Reblin (2010, p. 20) seria o "enredo que constitui o personagem em si, tanto na estrutura de sua história quanto em sua caracterização enquanto super-herói". Neste caso, a descrição dos super-heróis como personagens salvadoras (o que se percebe desde suas próprias mitologias de origem) propicia a discussão de temas teológicos. Por fim, "o religioso ou o teológico (ou o simbólico e o discurso sobre o sentido último da existência) pode estar presente nos elementos que perfazem a narrativa e a estética", elementos que podem "indicar não só anseios religiosos de uma coletividade, como expor as crenças e os anseios individuais de seus autores" (REBLIN, 2010, pp. 20,21). A partir destes vieses, e com as metodologias de interação entre teologia e literatura, pode-se empreender o estudo teológico das narrativas de superaventura em $\mathrm{HQ}$.

No entanto, é em sua premiada tese de doutorado sobre a potencialidade teológica da superaventura que luri Reblin (2012a) propõe um modelo teórico para o diálogo entre a teologia e os quadrinhos: a teologia do cotidiano ${ }^{1}$. Calcada no pensamento de

1. A tese foi publicada, mais tarde, em REBLIN, I. A.. O alienígena e o menino. Jundiaí, SP: Paco Editorial, 2015. 
Rubem Alves, Ivone Gebara, Pierre Bourdieu, Michel de Certeau, Clifford Geertz, entre outros, a teologia do cotidiano se constrói a partir de "elementos ou elaborações provenientes de uma religiosidade popular, de um imaginário religioso coletivo, atrelado ao contexto social de onde e para onde a história se destina" (REBLIN, 2012a, p. 153). Mais do que uma metodologia de pesquisa, tal teologia é uma prática reflexiva, uma atitude a partir da qual as experiências religiosas da vida cotidiana são concebidas, compreendidas e expressas. Neste sentido, pode-se dizer que

a teologia do cotidiano não é uma nova teologia, nem
outra corrente teológica, mas um termo formal que alu-
de à percepção de uma teologia que se imiscui nos
meandros da vida cotidiana; trata-se de uma teologia
constituída pelo sujeito ordinário no dia a dia e expressa
das mais diferentes maneiras. Em outras palavras, as
pessoas em sua vida diária não "apenas" têm experiên-
cias e vivências religiosas, mas procuram elaborar para
si e para outros, argumentativamente, o que essas ex-
periências significam. (REBLIN, 2012a, p. 154)

Como não existe uma única teologia do cotidiano, mas sim infinitas maneiras de se experimentar e de se expressar o religioso nas circunstâncias da vida, é possível que diferentes temas teológicos sejam extraídos de uma narrativa em quadrinhos, tantos quantos sejam os pontos de partida de quem se debruça sobre ela.

Reblin passa então à leitura analítica, à luz da teologia do cotidiano, de duas histórias de Paul Dini e Alex Ross: Superman: Paz na Terra, e Shazam: o Poder da Esperança. Este diálogo entre teologia e quadrinhos se dá a partir de três passos: a leitura do contexto da narrativa; a leitura do gênero da história narrada; e a investigação da deformação ou da reforma dos significantes reli- 
giosos empregados na narrativa ${ }^{2}$. Tudo isto, sem perder de vista a centralidade do mito nas histórias de superaventura (REBLIN, 2012a, p. 157).

Ao propor a teologia do cotidiano como modelo teórico para o diálogo entre a teologia e os quadrinhos, verificando a articulação e a apresentação de concepções e símbolos teológicos nas narrativas de super-heróis, Reblin ressalta que "a existência dessa mesma teologia cotidiana impulsiona uma abordagem teológica transversal e interdisciplinar da teologia" (REBLIN, 2012a, p. 156). Ou seja, a teologia do cotidiano é uma "teologia de fronteira", para fazer uso de um conceito associado ao pensamento de Paul Tillich.

Um outro texto em que Reblin aborda os quadrinhos a partir da teologia do cotidiano é "O Poder da Palavra", no qual o universo do mago Shazam e de seus Capitães Marvel é investigado, "a fim de verificar como tais histórias tornam-se o palco onde magia, mito e religião são representados e apresentados aos seus leitores" (REBLIN, 2012b, p. 110). Dialogando com Marcel Mauss, em seu Esboço para uma Teoria Geral da Magia, Reblin afirma que a magia é o eixo central do enredo das narrativas da Família Marvel, mediando os elementos mítico-religiosos que nelas aparecem. No entanto, na medida em que a magia se realiza nas histórias a partir da palavra - no caso, a expressão Shazam! - pode-se falar também na centralidade da palavra. "Religião, magia e mito se fundem e se confundem no poder da palavra" nestas narrativas, propõe

2. Este modelo é uma adaptação do que o próprio Reblin já havia elaborado em seus estudos de Mestrado. Naquele estudo, os passos para uma teologia do cotidiano eram: 1) Localizar símbolos, mitos e ritos aos quais as pessoas de um grupo ou de uma sociedade se apegam; 2) Compreendê-los na perspectiva do diálogo entre a história de um indivíduo ou grupo e seu contexto; 3) Realizar uma leitura crítica para que se perceba em que medida tais símbolos são uma recusa do mundo que se apresenta ou uma manutenção da realidade (REBLIN, 2007b, p. 141). 
Reblin (2012b, p. 115). Como característica de sua condição de fronteira, a teologia cotidiana pode interagir, por exemplo, com os estudos do Novo Testamento, ao ler a relação entre os personagens humanos dos quadrinhos e suas personas super-heroicas à luz do conceito paulino de carisma, como o faz Reblin (2012b, p. 116): "ao invocar seus nomes [mágicos], eles não apenas reconhecem a existência e a superioridade dessas personalidades, bem como compreendem as suas próprias ações como não suas, mas ações daqueles que eles invocam. É o sentido do carisma, conforme o Apóstolo Paulo".

Outro exemplo da aplicação da teologia cotidiana aos estudos das HQs é "Misticismo e religiosidade nas histórias de Penitência", em que Reblin (2013a) se debruça sobre a super-heroína (ou anti-heroína) brasileira Penitência, criada por Marcos Franco. Por ser uma produção nacional, e por se tratar de uma personagem construída a partir de temas religiosos e místicos, as histórias de Penitência permitem identificar elementos de uma teologia do cotidiano fundamentada na estrutura teológica do imaginário brasileiro.

Os referenciais teóricos mais importantes para a teologia do cotidiano são apresentados em outros estudos de luri Reblin. De um lado, em dois artigos sobre perspectivas hermenêuticas nas HQs, surge o nome de Michel de Certeau (REBLIN, 2013b; REBLIN, 2014a), que oferece bases para a perspectiva da centralidade da narrativa na própria constituição do mundo humano. De outro lado, a importância do pensamento alvesiano para a pesquisa de Reblin fica clara em "A contribuição de Rubem Alves para o estudo da teologia na arte sequencial" (REBLIN, 2015). Duas ideias de Alves são apropriadas por ele para o diálogo entre teolo- 
gia e quadrinhos (e a cultura pop, de uma forma geral): o conceito de estórias como invocações da vida e a concepção da teologia como atividade inerente ao ser humano, em sua busca por sentido. Percebe-se claramente, desde a própria expressão "teologia do cotidiano", emprestado de um livro de Rubem (REBLIN, 2015, p. 162), que Rubem Alves é o autor decisivo para se compreender a abordagem de Reblin.

Encerrando esta viagem pelos textos de luri Reblin, deve-se ressaltar o artigo "Intersecções entre Religião e Histórias em Quadrinhos" (REBLIN, 2014b), que propõe categorias interessantes e que serão utilizadas por outros autores em estudos posteriores. Uma abordagem na perspectiva da teologia e das ciências da religião identifica que religião e histórias em quadrinhos se encontram especialmente de quatro maneiras: a) quadrinhos produzidos por instituições religiosas; b) quadrinhos com temas reconhecidamente e intencionalmente religiosos; c) quadrinhos com religião como ilustração contextual; d) quadrinhos como expressão das estruturas simbólicas e religiosas (REBLIN, 2014b, p. 171). Além disso, são propostas três formas de aproximação entre a teologia e a superaventura: a) aproximação temática (com temas teológicos extraídos diretamente das narrativas); b) aproximação metodológica (em que se identifica a formação de personagens e histórias a partir da construção de mitos); c) aproximação ideológica (em que se percebe um ideal de vida projetado e compartilhado na narrativa) (REBLIN, 2014b, p. 175).

Outros autores têm abordado os quadrinhos a partir da reflexão teológica. No caso de Ruben Marcelino Silva, isto é feito utilizando a teologia do cotidiano como base teórica. Analisando a obra "O Homem de Aço", reelaboração das origens do Superman feita por 
John Byrne, Ruben Silva sugere a existência de três enunciados teológicos possíveis na HQ: "a teologia da dominação externa, a teologia da práxis altruísta e a teologia da subordinação do divino em favor do humano" (SILVA, 2016, p. 190). Este é um exemplo prático do uso da teologia do cotidiano no diálogo com os quadrinhos, segundo Silva (2016, p. 190), "no manejo particular de bens culturais e religiosos sem um compromisso rigoroso com formulações confessionais".

Renato Machado e Gelson Weschenfelder também pesquisam a interação entre teologia e quadrinhos no texto "Teologia, ética e perversão política em Watchmen" (MACHADO, WESCHENDFELDER, 2016). Analisando a série de histórias escrita por Alan Moore e ilustrada por Dave Gibbons, os autores se concentram nos personagens Ozymandias e Rorschach. A partir do diálogo com a teologia e com a filosofia (com referências a Lacan e a Żiżek), alguns temas teológicos são desenvolvidos, particularmente reflexões sobre o mysterium iniquitatis, a perversão da lei e a ética presente nos personagens.

Deve-se ressaltar também o trabalho recente de Carlos Caldas nos estudos teológicos das histórias em quadrinhos. Caldas cunha o termo "teologia nerd" para se referir ao diálogo com gêneros do cinema, TV, literatura e quadrinhos, de onde emergem temas como "ciborgues, androides, viagens no tempo e viagens intergalácticas, universos paralelos, inteligências artificiais, contato com alienígenas, passados alternativos, utopias e distopias de todo tipo, mutantes, seres humanos geneticamente modificados, fantasias heroicas" (CALDAS, 2015, p. 10).

Esta teologia nerd é empreendida por Caldas em "Das HQ's como discurso teológico", uma análise da história "Deus ama, o 
homem mata", de Chris Claremont, em que os heróis do supergrupo X-Men se vêem envolvidos num movimento de ódio contra os mutantes motivado pelo discurso fundamentalista religioso (CALDAS, 2017). Com base em teóricos como Tzvetan Todorov e Umberto Eco, Caldas investiga a obra de Claremont a partir do diálogo entre teologia e literatura. Deste diálogo, é possível extrair a concepção de salvação presente na narrativa, usando como referência a teologia de Paul Tillich. O conceito tillichiano de teologia de fronteira é então utilizado mais uma vez quando a teologia nerd é qualificada, segundo Caldas (2017, p. 78), como "uma teologia de fronteira, um 'desdobramento avançado', por assim dizer, de diálogos teológicos já estabelecidos com a literatura, o cinema, e as artes em geral".

Abordagem semelhante é feita por Carlos Caldas em "Religião e HQ's", onde se analisa o arco de histórias "Demolidor: diabo da guarda", de Kevin Smith e Joe Quesada (CALDAS, 2018). Neste caso, para fazer a leitura teológica do super-herói da Marvel, Caldas faz uso da análise estrutural de Karl-Joseph Kuschel e do diálogo entre literatura e teologia empreendido por Antonio Manzatto. Citando Manzatto, Caldas afirma que "pela literatura - e, como pretende-se mostrar neste artigo, pelas HQ's - a teologia pode acessar 'esferas do real que escapam à análise das ciências'" (CALDAS, 2018, p. 213). Reconhecendo a teologia e as HQs como dois pólos de um diálogo intercultural, nos termos da analogia estrutural, Carlos Caldas identifica e discute dois temas teológicos principais na narrativa do Demolidor: o problema do mal e a questão da fé e da dúvida.

Deve-se destacar, por fim, a dissertação de mestrado em literatura de Stéphanie Spengler (2018), que investiga os quadrinhos 
de "Um Sábado Qualquer", obra do artista Carlos Ruas. Em "Texto e paratexto", Spengler busca estabelecer relações entre quadrinhos, teologia e literatura, fazendo uso da teopóetica de Robert Alter e Antônio Magalhães e da crítica literária de Tzvetan Todorov, dentre outros. É na análise dos textos e paratextos dos quadrinhos criticamente cômicos de Ruas que Spengler busca os sentidos teológicos da obra.

\section{Quadrinhos e Ciências da Religião}

A maior parte da pesquisa sobre a relação entre religião e $\mathrm{HQ}$ se enquadra nos campos das ciências da religião. A religião é percebida nos quadrinhos a partir da sociologia, da filosofia, da psicologia, dos estudos literários, das questões de gênero, da representatividade afrobrasileira, da liturgia, dentre outros saberes.

Um estudo singular sobre a identificação e o mapeamento dos quadrinhos brasileiros conforme sua relação com os grupos religiosos nacionais é "Configurações das religiosidades no quadrinho brasileiro", de Amaro Xavier Braga Junior (2015). Os quadrinhos brasileiros são agrupados por semelhança ou proximidade, de acordo com as tradições religiosas, em quatro grandes matrizes: a afro-brasileira, a kardecista, a cristã e a esotérica. Para a seleção das publicações relacionadas aos movimentos religiosos, Braga Junior levou em conta a "a pré-determinação dos autores no vínculo entre os dois temas (quadrinhos e religião), a natureza do enredo da revista, seu descritor e/ou resumo, assim como o título do material; e, os agentes envolvidos na sua produção e/ou circulação" (BRAGA JUNIOR, 2015, p. 173). A pesquisa é exaustiva, analisando a produção nacional relacionada à religião de 1960 a 2014. 
Braga Junior elabora uma importante categorização quanto à natureza da origem das publicações em quadrinhos brasileiros em sua relação com a religião. Segundo ele, estas histórias em quadrinhos podem ser classificadas em: a) Produção institucional, no caso de terem sido financiadas e orientadas por instituições ou líderes religiosos; b) Referência fragmentada ou neutra, "onde o elemento religioso foi um elemento secundário acrescentado na produção sem destaque ou, simplesmente, sem vínculos institucionalizados declarados"; c) Produção satírico-crítica, em que se apresentam visões negativas, críticas ou estereotipadas do fenômeno religioso; e d) Produções simbólico-representacionais, nas quais "a essência religiosa pode ser percebida pelo leitor/pesquisador, mas sem que esta ligação seja declarada abertamente" (BRAGA JUNIOR, 2015, p. 183).

Por fim, Braga Junior confronta o número de publicações em cada matriz religiosa. Segundo ele, não há como comparar, em número absoluto, as HQs de temática cristã com as demais matrizes. $\mathrm{E}$, dentre este elevado número de publicações, as produções evangélicas correspondem a mais de dois terços do total. Para Braga Junior (2015, p. 187), a explicação para esta diferença significativa no número de publicações se daria pela prática do proselitismo pelas denominações cristãs, pela necessidade de educação religiosa das crianças e pelas necessidades de expansão deste segmento.

A sociologia da religião é o marco teórico conceitual usado por Emmanuel Rocha (2014) em "Expressões literárias do reencantamento do mundo". Rocha se detém sobre a obra "Promethea", de Alan Moore, "buscando identificar quais são os elementos do ocultismo e como estes e a própria obra de Moore se inserem no pro- 
cesso de reencantamento do mundo" (ROCHA, 2014, p. 181). O autor discute o conceito de reencantamento do mundo a partir da popularização do ocultismo e investiga a vantagem que as HQ têm neste processo, na medida em que aliam narrativa e arte gráfica.

Alguns textos da interface entre ciências da religião e quadrinhos tratam das representações religiosas presentes nas narrativas. É o caso de "Super-heróis como Messias", de Fábio Vieira Guerra (2015). A partir do conceito de monomito americano, de John Lawrence e Robert Jewett, Guerra discute "a presença de elementos religiosos nas narrativas apresentadas nas histórias em quadrinhos da editora Marvel Comics", entre as décadas de 1980 e 2000 (GUERRA, 2015, p. 79). Se, num primeiro momento, as revistas da Marvel apresentavam a religião de forma mais velada, a partir da elaboração de narrativas com conteúdo mais adulto, os símbolos de fé começam a aparecer nas histórias. Além disso, segundo Guerra (2015, p. 93), elementos importantes relacionados à teologia e ao mito também começam a surgir, como "a angústia de um paraíso perdido, a nomeação de um salvador, a batalha épica do bem contra o mal, e a busca da imortalidade".

As questões de gênero também encontram o seu lugar na pesquisa sobre religião e HQs. Em "Representações do Feminino", Kathlen de Oliveira e luri Reblin (2011) discutem como o gênero e a religião são representados e compreendidos nos quadrinhos, em especial nas histórias das super-heroínas Mulher-Maravilha, Penitência e Velta (estas últimas, personagens de produções brasileiras). Na percepção de Oliveira e Reblin (2011, pp. 437, 438), se de um lado "o protagonismo das super-heroínas evidencia a passagem da mulher dona de casa, da frágil e inocente a uma mulher que almeja independência, que se mete na política e em 
qualquer questão pública", de outro lado "surgem novos tipos de reprodução, de preconceitos e simplificações do corpo feminino, mesmo que a distância entre a heroína e a vilã, a mocinha e a vagabunda estejam diluídas".

Discussão semelhante é realizada por Natania Nogueira (2015) em "Mulheres, política, religião e bande dessinée”. Partindo do pressuposto que, "na história das mulheres, a religião foi muito mais opressora do que agregadora", identifica-se as histórias em quadrinhos como um dos espaços de resistência feminina (NOGUEIRA, 2015, pp. 17, 18). Um dos diferenciais deste texto é que Nogueira se debruça sobre o universo dos quadrinhos francófonos (enquanto que quase toda a totalidade dos estudos se concentra nos quadrinhos norte-americanos e brasileiros). Com o foco nas HQs produzidas por mulheres, Nogueira investiga como são representados o preconceito e a repressão contra a mulher no contexto da religião.

Outro artigo interessante é "Política e Evangelização em quadrinhos", da historiadora Gisele Oliveira de Lima (2013a). A autora pesquisa o trabalho sacerdotal do padre Paolo Tonucci na cidade de Salvador, discutindo a importância das histórias em quadrinhos (produzidas pelo próprio padre) para a evangelização na perspectiva da teologia da libertação no final da década de 1970. Gisele Lima retoma esta discussão ao analisar a $\mathrm{HQ}$ "Abrir las puertas a un nuevo mundo: Puebla", produzida por Paolo Tonucci, em 1979, para retratar o ambiente em Puebla após a Conferência do Conselho Episcopal Latino Americano (LIMA, 2013b).

As $H Q$ são também um espaço de representação da cultura e religião afro-brasileiras. Nobu Chinen, em "A religiosidade afro-brasileira nos quadrinhos", levanta a "presença de temas ligados 
à religiosidade de matriz africana nas publicações de quadrinhos brasileiras para verificar sua pertinência e o grau de fidelidade aos conceitos e práticas adotadas" (CHINEN, 2013, p. 41). Segundo ele, até a década de 1990, os cultos religiosos africanos eram representados nas HQs, notadamente em narrativas de terror, sob o viés da invocação de forças demoníacas, explorando o aspecto mágico e sobrenatural dos ritos e feitiçarias. O marco histórico da mudança na abordagem é a lei 10.369, de 2003, que institui a obrigatoriedade do ensino da cultura afro-brasileira. A partir de então, de acordo com Chinen (2015, p. 45), "se antes predominava o lado místico-sobrenatural, mais voltado à magia e ao ocultismo, há, nas representações atuais, a preocupação com o aspecto cultural e de preservação das crenças e rituais do candomblé e da umbanda".

Ruben Marcelino Silva igualmente discute o tema em "A didática lúdica de Exu", onde propõe uma aproximação à cultura afro-brasileira a partir da publicação em quadrinhos "AfroHQ", de Amaro Braga, Danielle Jaimes e Roberta Cirne (SILVA, 2013). Em seu texto, Silva discute a questão da identidade afro-brasileira a partir de quatro temas que "ilustram a relação simbólica entre os Orixás e a história dos negros no Brasil: ancestralidade, escravidão, resistência e contribuições para a cultura nacional" (SILVA, 2013, p. 55). Ao estabelecer esta discussão, o autor não apenas examina a cultura afro-brasileira na publicação em questão, como também ressalta o potencial de "AfroHQ" para transmitir o conhecimento desta cultura.

São vários os textos que abordam a relação entre religião e quadrinhos a partir dos estudos literários. É o caso, por exemplo, de "Entre a religião e os quadrinhos", de Alex Caldas Simões (2015). Neste artigo, Simões estuda a identidade discursiva do 
personagem Kurt Wagner, o Noturno dos X-Men, na publicação "X-Men Origens: Noturno". Fazendo uso da análise do discurso francesa, particularmente dos conceitos de ethos discursivo e de cena enunciativa, o autor discute como a religião católico é articulada, de alguma forma, com a identidade discursiva de Noturno. Por fim, Simões propõe o aporte teórico da análise do discurso para outros estudos futuros sobre quadrinhos.

Em "O aspecto secular-religioso dos Peanuts", David Lira se aproxima da obra de Charles Schulz a partir da análise teolinguística, como proposta por David Crystal (LIRA, 2016). Segundo Lira, expondo o pensamento de Crystal, "a teolinguística é "um termo que tem sido usado para o estudo da relação entre a linguagem e o pensamento e prática religiosa, como ilustrado pelo ritual, textos sagrados, pregação, declarações doutrinais e afirmações privadas de fé" (LIRA, 2016, pp. 49, 50). No caso de Schulz e seus personagens do universo do menino Charlie Brown, não se trata tanto da linguagem litúrgica ou bíblica, mas sim da linguagem prática da prédica. Pode-se identificar nos quadrinhos de Schulz, de acordo com Lira (2016, p. 54), a "pragmática da linguagem do sermão aconselhador e encorajador em vários contextos sociais".

De igual modo, a temática da intertextualidade aparece em alguns estudos sobre quadrinhos e religião. É o que se dá, por exemplo, em "A intertextualidade entre $O$ Reino do Amanhã e o Apocalipse" e "História em quadrinhos e religião". No primeiro artigo, Letícia de Oliveira e Nataniel dos Santos Gomes (2013) investigam a relação intertextual da $\mathrm{HQ}$ "O Reino do Amanhã", de Mark Waid e Alex Ross, com o livro bíblico do Apocalipse. Esta produção é muito propícia a este tipo de estudo, dada a grande quantidade de citações bíblicas e referências - imagéticas e tex- 
tuais - a elementos da fé cristã. No segundo artigo, Ramon Solles e Nataniel dos Santos Gomes (2014) realizam a mesma investigação intertextual, com o foco agora na relação entre as figuras de Superman (na obra citada de Waid e Ross, no filme "Homem de Aço", dirigido por Zack Snyder, e na animação "Liga da Justiça") e o Jesus Cristo apresentado nos escritos do Novo Testamento. Por conta do referencial teórico em Mikhail Bakhtin, a discussão se dá em termos de interdiscursividade e do conceito bakhtiniano de dialogismo (SOLLES, GOMES, 2014, p. 270).

Um último exemplo de abordagem ao universo dos quadrinhos a partir das ciências da religião é o artigo "Movimento cosplay e insinuações litúrgicas”, de Paulo Felipe Almeida (2016). Com base em Rubem Alves e Luiz Carlos Ramos, o autor propõe uma aproximação entre o movimento cosplay - de representação, em conferências e festas, dos personagens dos quadrinhos por meio de fantasias e gestuais - e a experiência litúrgica. Ambos se aproximam por meio da busca pelo grande herói e sua narrativa, pela experiência de veneração/adoração, pela procura por uma referência, e pela comunhão do espaço de encontro.

\section{Histórias em Quadrinhos e Ensino Religioso}

Alguns dos estudos sobre a relação entre religião e HQ abordam, de maneira direta ou indireta, a possibilidade do uso das narrativas em quadrinhos como recurso para a atividade de ensino religioso.

O texto que trata mais diretamente do tema é "Quadrinhos nas aulas de Ensino Religioso”, de luri Reblin (2016). Utilizando a já referida categoria da teologia do cotidiano, Reblin delineia os pontos de contato entre as HQs e a experiência religiosa, além de dis- 
sertar sobre a possibilidade de se dirigir um olhar teológico à arte sequencial. De forma muito prática, o artigo aborda o potencial dos quadrinhos como recurso para aulas de ensino religioso "a partir de uma experiência docente em um curso de capacitação ministrado para docentes da educação básica promovida pela Coordenação Regional de Educação do Estado do Rio Grande do Sul" (REBLIN, 2016, p. 15). Neste mesmo texto, Reblin propõe uma revisão dos pontos de intersecção entre religião e história em quadrinhos (apresentados em REBLIN, 2014b), agora identificados como "a) Quadrinhos como produção religiosa. b) Quadrinhos com temas reconhecidamente religiosos. c) Quadrinhos como expressão do universo simbólico e de sentido" (REBLIN, 2016, p. 26).

Outro artigo que se detém sobre o uso de histórias em quadrinhos no ensino religioso (neste caso, mais especificamente, o estudo da história das religiões) é "Crônicas da Terra Santa", de Cristine Fortes Lia e Daniel Clós Cesar (2015). A história em questão é a obra do artista Guy Delisle “Crônicas de Jerusalém”, diário ilustrado que retrata um ano morando naquela cidade. Para Lia e Cesar, a obra de Delisle é uma excelente ferramenta para se utilizar no ensino de história das religiões na medida em que, sem "tomar partido entre as diferentes sociedades e culturas religiosas que dividem espaço geográfico e espiritual na cidade santa", ela faz "uma descrição gráfica do cotidiano na cidade que é sagrada para as três religiões monoteístas" (LIA, CESAR, 2015, p. 139).

Não se deve esquecer também da dissertação de mestrado em educação de Daniel Clós Cesar (2015), "Ensino de história das religiões". O texto de Cesar faz um levantamento histórico do uso das HQs na educação e da forma como ensino de História das Religiões é apresentado em sala de aula, estabelece uma crítica 
ao ensino religioso como divulgação de doutrinas específicas e apresenta modelos de atividades práticas para auxílio do docente.

\section{Quadrinhos e Divulgação Religiosa}

No estudo da interface entre religião e quadrinhos, surgem os textos que tratam das HQs como mídia para a divulgação religiosa, tanto do ponto de vista institucional quanto da parte de indivíduos e movimentos.

Valéria Aparecida Bari e Glêyse Santos Santana (2015), em "A obra quadrinhística de Marcio Baraldi e suas representações religiosas", estudam a obra do artista brasileiro Marcio Baraldi, problematizando os usos, interpretações e sentidos que editores e leitores fazem desta obra. Partindo do conceito de letramento situado, de Márcia Mendonça, as autoras reconhecem o uso das HQs em situações específicas, como propaganda institucional, didatização e divulgação científica, que podem ser aplicadas aos quadrinhos de Baraldi. O interesse principal de Bari e Santana está nos personagens criados com a intenção de suscitar a discussão metafísica: os passarinhos Vapt e Vupt. "Nos quadrinhos de Vapt e Vupt", afirmam elas, "as representações metafísicas do mundo espiritual, da esfera divina, dos princípios e filosofia Crística, são fundamentados pela obra filosófica Kardecista brasileira, que é ligeiramente diferente de sua matriz original europeia" (BARI, SANTANA, 2015, p. 159). Desta forma, os quadrinhos de Baraldi (particularmente as histórias de Vapt e Vupt) servem como plataforma para a divulgação do kardecismo brasileiro.

O artigo de Karina Kosicki Bellotti (2015), “Mangá Messias'entre ressurreições e reencarnações de Jesus", tem a singularidade de relacionar religião e mangá (estilo japonês de HQ). Bellotti ana- 
lisa as diferentes representações de Jesus Cristo nos quadrinhos a partir da segunda metade do século $X X$, com ênfase especial na obra "Mangá Messias", produção juvenil que visa divulgar a fé cristã para as novas gerações. Com base na obra de Stephen Prothero, diferenciam-se as ressurreições e as reencarnações de Jesus: as ressurreições são as recriações feitas por grupos cristãos que mantiveram a imagem de Jesus dentro da tradição cristã; as reencarnações são as recriações de grupos não-cristãos que ressignificaram esta imagem à luz de outras tradições religiosas (BELLOTTI, 2015, p. 111). A partir do “Mangá Messias", Bellotti passa a investigar estas ressurreições e reencarnações da imagem de Jesus nas histórias em quadrinhos.

A contradição entre o uso dos quadrinhos como mídia de divulgação religiosa do adventismo e as reações críticas presentes na Revista Adventista é o objeto do artigo "As histórias em quadrinhos e o adventismo brasileiro", de Felipe Carmo e Allan Novaes (2015). Com a proposta de sistematizar o pensamento adventista a respeito das HQs, os autores reconhecem que "o gênero da arte sequencial é utilizado na IASD [Igreja Adventista do Sétimo Dia] como ferramenta para a disseminação de seus interesses" (p. 1177). As críticas presentes no órgão oficial da instituição, no entanto, têm conferido "cada vez menos motivação para a produção de HQs em prol do pensamento bíblico ideológico da denominação" (CARMO, NOVAES, 2015, p. 1178).

\section{Quadrinhos como Expressão Espiritual ou Arte Visionária}

Algumas HQs brasileiras, que têm sido reconhecidas como HQs de fantasia filosófica ou poético-filosóficas, são elas mesmas modos de expressão de poesia e espiritualidade. Menos relacio- 
nadas às religiões institucionais, estas histórias, em alguns casos, chegam a se constituir como manifestação artística da experiência mística, sendo qualificadas como arte visionária.

Em "O que são histórias em quadrinhos poético-filosóficas?", Elydio Santos Neto (2009) examina a origem deste gênero no Brasil, que tem como representantes, dentre outros, Flávio Calazans, Edgar Franco e Gazy Andraus. Estes quadrinhos tendem a ser herméticos, representando "uma viagem muito interiorizada dos autores" (SANTOS NETO, 2009, p. 76). Um exemplo radical deste hermetismo é a obra "Absurdos", produzida por Flávio Calazans e Paulo Prata em processo espontâneo de criação e sob hipnose.

O principal interlocutor de Santos Neto no artigo é o artista e acadêmico Gazy Andraus, a partir de uma entrevista concedida. Para Andraus, as HQs poético-filosóficas apresentam seus autores como visionários, sujeitos que enxergam outras nuanças da realidade, afirma Gazy Andraus (apud SANTOS NETO, 2009, p. 80). Ainda de acordo com Andraus, ao revelar a seriedade, a busca da sabedoria e a espiritualidade inerente em seus temas, estes quadrinhos poderiam ser denominados $\mathrm{HQs}$ espiritualistas. Esta qualificação só não é totalmente apropriada "por causa dos preconceitos concernentes às questões de ordens espirituais" (apud SANTOS NETO, 2009, p. 81). De alguma forma, os quadrinhos poético-filosóficos são a contra-parte dos haikais. Nas palavras de Andraus (apud SANTOS NETO, 2009, p. 88), são "mensagens condensadas, visuais-literárias, para quebrar a mente racional, tal como os koans zen-budistas são utilizados pelos mestres para trazerem a mente cósmica a seus discípulos".

Santos Neto (2007) também aborda os quadrinhos de Andraus como mensagens koânicas, ao estilo zen-budista, em "Os quadri- 
nhos poético-filosóficos de Gazy Andraus". Neste texto, o processo criativo de Andraus é destrinchado, retratando a influência do taoísmo "na vida e obra deste artista que, coerente com esta visão de mundo, busca deixar fluir livremente em si as vibrações que sua sensibilidade consegue captar" (SANTOS NETO, 2007. p. 9). Estas HQs tem como preocupação, de acordo com Santos Neto (2007, p. 6), muito mais a religação com o cosmo e a manifestação da consciência cósmica do que a comunicação racional de uma narrativa.

A investigação do koan zen-budista nos quadrinhos já havia sido proposta na dissertação de mestrado de Gazy Andraus (2009), "Existe o quadrinho no vazio entre dois quadrinhos?". Andraus qualifica o koan como "uma forma de pergunta, em forma de enigma indecifrável pelos padrões lógicos racionais vigentes. Uma forma de pergunta, para a qual não possui resposta imediata racional, que busca derrubar toda a estrutura condicionada da mente racional" (ANDRAUS, 2009, p. 77). A HQ koânica, segundo Andraus (2009, p. 94), traria consigo amalgamados elementos do zen-budismo, do taoísmo, da física quântica e do misticismo holístico. Ele passa, então, a discutir a presença do koan na obra de vários autores, como Grant Morrison, Alan Moore, Jim Starlin, Stan Lee, Antônio Amaral, Andrea Pazienza e Edgar Franco.

Alguns estudos tratam do processo criativo deste gênero de HQs. É o caso de "Agartha”, de Edgar Franco e Danielle Fortuna (2015), que analisa a produção da história de mesmo título, de autoria do próprio Franco. Em "Agartha", segundo os autores, tem-se "uma versão mítica da criação do mundo e a saga de um homem que representa a busca do mito arquetípico de um paraíso/éden existente em diversas religiões ao redor do planeta, como no 
Cristianismo, Judaísmo e Maometanismo" (FRANCO, FORTUNA, 2015, p. 37). O criador de "Agartha" situa a narrativa em consonância com as religiões orientais, em que os deuses manifestam suas leis diretamente, sem intermediários, religiões da iluminação individual e do êxtase místico (FRANCO, FORTUNA, 2015, p. 41). É neste sentido que, mais do que contar uma história, o álbum pretende expressar a saga de cada ser humano pela transcendência, o que Santos Neto $(2008$, pp. 9,10$)$ caracteriza como "a ousadia de propor o resgate dos antigos 'rituais' (= tecnologias do humano e do sagrado) que favoreciam a re-ligação interna do ser humano".

Por fim, destaca-se a interessante pesquisa de Matheus Moura Silva sobre processos criativos a partir de estados não-ordinários de consciência (ENOC). Em "Ayahuasca e a influência na criação de Íncaro", Silva (2015) analisa a obra do artista brasileira Xalberto, que produz seus quadrinhos sob a influência da beberagem indígena chamada Ayahuasca. Matheus Silva situa a obra de Xalberto no que chama de arte visionária, a representação plástica de "experiências concretas de um universo invisível ao qual têm acesso o artista, o xamã, o místico e alguns outros" (SILVA, 2015, p. 73). A HQ Íncaro, surgida no seio da prática religiosa e psicodélica da União do Vegetal, é portanto um exemplo de criação dentro do contexto xamânico a partir de ENOC.

Matheus Silva (2017) faz o mesmo tipo de análise em "Quadrinhos visionários de Sergio Macedo", onde a obra do artista brasileiro é resgatada e investigada. Sob a influência de alucinógenos, numa primeira fase, e posteriormente da técnica hindu conhecida como respiração prânica, Macedo produz seus quadrinhos a partir de experiências com ENOC, qualificados como desenhos rituais que promovem uma alquimia mental e proporcionam uma verdadeira "trajetória reli- 
giosa em direção à luz" (SILVA, 2017, p. 99).

\section{Conclusão}

Ainda que incipiente, a pesquisa sobre história em quadrinhos a partir dos estudos da religião no Brasil já tem material suficiente para que novas abordagens sejam estabelecidas com um diálogo profícuo. A capacidade única de integrar narrativa e imagens presente na arte sequencial tem seu contraponto natural na experiência religiosa, também eivada de imagens e histórias. Daí abrirem-se caminhos possíveis para a investigação neste campo.

Ainda há áreas que carecem de um maior aprofundamento, como é o caso dos estudos sobre o uso das HQs no ensino religioso, e outras que possibilitam novos desdobramentos, como a análise das relações entre zen-budismo, xamanismo, estados não-ordinários de consciência e processo criativo. Mas, seja como for, já há referenciais a partir dos quais a exploração pode ser feita.

Em artigo recente, Carlos Caldas vaticina que "nos próximos anos haverá aumento na pesquisa e na produção acadêmica no Brasil nesta área", e que "em alguns anos deverá existir um número considerável de produções neste sentido" (CALDAS, 2018, p. 221). A pretensão deste estudo que se encerra é estimular a produção no diálogo quadrinho e religião, contribuindo para que esta profecia se cumpra.

\section{Referências}

ANDRAUS, Gazy. Existe o quadrinho no vazio entre dois quadrinhos? (ou: o Koan nas histórias em quadrinhos autorais adultas). Dissertação (Mestrado em Artes Visuais). São Paulo: Universidade Estadual Paulista, 2009.

ALMEILDA, Paulo Felipe Teixeira. Movimento cosplay e insinuações litúrgicas. In: REBLIN, I. A.; MACHADO, R. F.; WESCHENFELDER, G. (Orgs.). Vamos 
falar sobre quadrinhos? Retratos teóricos a partir do sul. Leopoldina: ASPAS, 2016, pp. 271-283.

BARI, Valéria Aparecida; SANTANA, Glêyse Santos. A obra quadrinhística de Marcio Baraldi e suas representações religiosas. In: BRAGA, A. (Org.); REBLIN, luri Andréas (Org.). Religiosidades nas histórias em quadrinhos. 1. ed. Leopoldina/MG: ASPAS, 2015, pp. 155-169.

BELLOTTI, Karina Kosicki. "Mangá Messias" entre ressurreições e reencarnações de Jesus - uma história cultural das figuras de Jesus nas histórias em quadrinhos. In: BRAGA, A. (Org.); REBLIN, luri Andréas (Org.). Religiosidades nas histórias em quadrinhos. 1. ed. Leopoldina/MG: ASPAS, 2015, pp. 109-137.

BRAGA JUNIOR, Amaro Xavier. Configurações das religiosidades no quadrinho brasileiro. In: BRAGA, A. (Org.); REBLIN, luri Andréas (Org.). Religiosidades nas histórias em quadrinhos. 1. ed. Leopoldina/MG: ASPAS, 2015, pp. 171-190.

CALDAS, Carlos. Das HQ's como discurso teológico: análise de X-Men - Deus ama, o homem mata, de Chris Claremont na perspectiva da soteriologia de Paul Tillich. Teoliterária, v. 7, n. 14, 2017, pp. 70-90.

CALDAS, Carlos. Religião e HQ's: análise de Demolidor: diabo da guarda, de Kevin Smith e Joe Quesada. NUMEN: Revista de Estudos e Pesquisa da Religião, v. 21, p. 211-222, 2018.

CARLOS, Caldas (Org.). Teologia nerd. São Paulo: Garimpo Editorial, 2015.

CARMO, Felipe; NOVAES, Allan. As histórias em quadrinhos e o adventismo brasileiro: conflitos e aproximações na Revista Adventista. Belo Horizonte, MG. Anais do 28 Congresso Internacional da Soter, 2015, pp. 11731181.

CESAR, Daniel Clós. Ensino de história das religiões: cristianismo, islã e judaísmo nas histórias em quadrinhos. Dissertação (Mestrado em História). Caxias do Sul: Universidade de Caxias do Sul, 2015.

CHINEN, Nobu. A religiosidade afro-brasileira nos quadrinhos. Identidade!, v.18, n. 1, 2013, pp. 39-54.

FRANCO, Edgar Silveira; FORTUNA, Danielle Barros Silva. Agartha: processo criativo de uma HQ poético-filosófica sobre o Éden mítico. In: BRAGA, A. (Org.); REBLIN, luri Andréas (Org.). Religiosidades nas histórias em quadrinhos. 1. ed. Leopoldina/MG: ASPAS, 2015, pp. 37-59.

GUERRA, Fábio Vieira. Super-heróis como Messias: a religiosidade presente nas histórias da Marvel Comics (1980-2010). In: BRAGA, A. (Org.); REBLIN, luri Andréas (Org.). Religiosidades nas histórias em quadrinhos. 1. ed. Leopoldina/MG: ASPAS, 2015, pp. 79-94. 
LIA, Cristine Fortes; CESAR, Daniel Clós. Crônicas da Terra Santa: o diário ilustrado de Guy Delisle. In: BRAGA, A. (Org.); REBLIN, luri Andréas (Org.). Religiosidades nas histórias em quadrinhos. 1. ed. Leopoldina/MG: ASPAS, 2015, pp. 139-153.

LIMA, Gisele Oliveira de. Política e Evangelização em quadrinhos. Clio. Série História do Nordeste (UFPE), v. 31.2, 2013a, pp. 1-20.

LIMA, Gisele Oliveira de. Será por HQ, será numa língua bárbara que a teologia da libertação falará a poucos. XXVII Simpósio Nacional de História. Caderno de Resumos. Natal, RN, 2013b, pp. 1-21.

LIRA, David Pessoa de. $O$ aspecto secular-religioso dos Peanuts: uma análise teolinguística da prédica de Charles Schulz através da narrativa figurada. Estudos Teológicos (Online), v. 56, 2016, pp. 40-54.

MACHADO, Renato Ferreira. Guerra Civil: a crise dos mitos na Marvel. In: REBLIN, I. A.; MACHADO, R. F.; WESCHENFELDER, G. (Orgs.). Vamos falar sobre quadrinhos? Retratos teóricos a partir do sul. Leopoldina: ASPAS, 2016, pp. 171-185.

MACHADO, Renato Ferreira, WESCHENFELDER, Gelson. Teologia, ética e perversão política em Watchmen. Estudos Teológicos (Online), v. 56, 2016, pp. 55-68.

NOGUEIRA, Natania A. Silva. Mulheres, política, religião e bande dessinée. In: BRAGA, A. (Org.); REBLIN, luri Andréas (Org.). Religiosidades nas histórias em quadrinhos. 1. ed. Leopoldina/MG: ASPAS, 2015, pp. 17-35.

OLIVEIRA, Kathlen Luana de; REBLIN, luri Andréas. Representações do Feminino: embates acerca da sexualidade e da religiosidade. Anais do I Encontro Nacional de Estudos sobre Quadrinhos e Cultura Pop. Maceió: Edufal, 2011, p. 430-445.

OLIVEIRA, Letícia Reis de; GOMES, Nataniel dos Santos. A intertextualidade entre O Reino do Amanhã e o Apocalipse. Revista Philologus, Suplemento, Ano 19, N55, 2013, pp. 54-64.

REBLIN, luri Andréas. A contribuição de Rubem Alves para o estudo da teologia na arte sequencial: anotações de um fragmento de mosaico misturadas com biografia. Reflexus - revista eletrônica de teologia e ciências das religiões, v. 8, 2015a, pp. 155-168.

REBLIN, luri Andréas. A superaventura: da narratividade e sua expressividade à sua potencialidade teológica. Tese (Doutorado em Teologia). São Leopoldo: Escola Superior de Teologia, 2012a.

REBLIN, luri Andréas. A teologia e a saga dos super-heróis: valores e crenças apresentados e representados no gibi. Protestantismo em Revista, v. 22, 2010, pp. 13-21. 
REBLIN, luri Andréas. Hermeneutical perspectives on the theology of daily life in comic book Stories. Estudos Teológicos, v. 54, 2014a, pp. 125-139.

REBLIN, luri Andréas. Intersecções entre Religião e Histórias em Quadrinhos: balões de pensamento a partir de um olhar à superaventura. Paralellus (Online), v. 5, 2014b, pp. 161-178.

REBLIN, luri Andréas. Misticismo e religiosidade nas histórias de Penitência. Revista Espaço Acadêmico (UEM), v. 12, 2013a, pp. 35-44.

REBLIN, luri Andréas. O alienígena e o menino. Jundiaí, SP: Paco Editorial, 2015b.

REBLIN, Iuri Andréas. O Poder da Palavra: magia, mito e religião em Shazam!. Revista Espaço Acadêmico (UEM), v. 12, 2012b, pp. 109-117.

REBLIN, Iuri Andréas. O X da Questão: evolução, alteridade e preconceito como desafios à tolerância: uma leitura a partir dos X-Men. Protestantismo em Revista, v. 12, 2007a, pp. 114-125.

REBLIN, luri Andréas. "Para o alto e avante!": Mito, religiosidade e necessidade de transcendência na construção dos super-heróis. Protestantismo em Revista, São Leopoldo/RS, v. 07, n.2, 2005, pp. 32-50.

REBLIN, luri Andréas. Perspectivas hermenêuticas acerca da representação religiosa nas histórias em quadrinhos. Nona Arte: Revista Brasileira de Pesquisas em Histórias em Quadrinhos, v. 2, 2013b, pp. 37-52.

REBLIN, Iuri Andréas. Quadrinhos nas aulas de Ensino Religioso: subsídios e práticas pedagógicas de uma experiência docente. Estudos Teológicos (Online), v. 56, 2016, pp. 12-39.

REBLIN, Iuri Andréas. Super-heróis e religiosidade: um ensaio para iniciar um debate. Revista Espaço Acadêmico (UEM), v. ano 7, p. n. 72, 2007b.

REBLIN, luri Andréas. Teologia: outros cheiros, outros sabores... a teologia na perspectiva crítica e poética de Rubem Alves: caminhos para uma teologia do cotidiano. Dissertação (Mestrado em Teologia). São Leopoldo: Escola Superior de Teologia, 2007c.

ROCHA, Emmanuel Ramalho de Sá. Expressões literárias do reencantamento do mundo: Promethea de Alan Moore. Paralellus (Online), v. 5, 2014, pp. 161-178.

SANTOS NETO, Elydio. O que são histórias em quadrinhos poético-filosóficas? Um olhar brasileiro. Visualidades (UFG), v. 7, 2009, p. 69-99.

SANTOS NETO, Elydio. Os quadrinhos poético-filosóficos de Gazy Andraus: provocações de uma visão crítica, espiritual e afirmativa da vida. Anais do XXX Congresso Brasileiro de Ciências da Comunicação, 2007.

SANTOS NETO, Elydio. Transgressão, transcendência e esperança: os quadrinhos poético-filosóficos de Edgar Franco. Anais do XXXI Congresso Brasileiro 
de Ciências da Comunicação, 2008.

SILVA, Matheus Moura. Ayahuasca e a influência na criação de Íncaro: estórias daquele que voou. In: BRAGA, A. (Org.); REBLIN, luri Andréas (Org.). Religiosidades nas histórias em quadrinhos. 1. ed. Leopoldina/MG: ASPAS, 2015, pp. 61-78.

SILVA, Matheus Moura. Quadrinhos Visionários de Sergio Macedo. Art \& Sensorium, v. 4, 2017, pp. 97-116.

SILVA, Ruben Marcelino Bento. A didática lúdica de Exu: uma aproximação à exuberância da cultura afro-brasileira conforme retratada no álbum em quadrinhos "AfroHQ". Identidade!, v.18, n. 1, 2013, p. 55-66.

SILVA, Ruben Marcelino Bento. "Krypton deu origem ao Superman mas a Terra me transformou em um ser humano": rascunho de teologias possíveis expressas em $\mathrm{O}$ Homem de Aço, de John Byrne. In: REBLIN, I. A.; MACHADO, R. F.; WESCHENFELDER, G. (Orgs.). Vamos falar sobre quadrinhos? Retratos teóricos a partir do sul. Leopoldina: ASPAS, 2016, pp. 187-198.

SIMÕES, Alex Caldas. Entre a religião e os quadrinhos: a identidade discursiva de Kurt Wagner dos X-Men. In: BRAGA, A. (Org.); REBLIN, luri Andréas (Org.). Religiosidades nas histórias em quadrinhos. 1. ed. Leopoldina/ MG: ASPAS, 2015, pp. 95-108.

SPENGLER, Stéphanie. Texto e paratexto: construção de sentidos em Um Sábado Qualquer. Dissertação (Mestrado em Literatura). Florianópolis: Universidade Federal de Santa Catarina, UFSC, 2018.

SOLLES, Ramon Amancio; GOMES, Nataniel dos Santos; ARANTES, Taís Turaça. História em quadrinhos e religião: uma análise da figura de Superman. Cadernos do CNFL, Vol. XVIII, № 09, 2014, pp. 269-279.

XAVIER, Cristina L. M. Spawn, o soldado do inferno - mito e religiosidade nos quadrinhos. São Paulo: Difusão, 2004. 